\title{
Experimental treatment of antipsychotic-induced movement disorders
}

This article was published in the following Dove Press journal:

Journal of Experimental Pharmacology

8 August 2016

Number of times this article has been viewed

\section{Erum Shireen}

Department of Biochemistry, Neurochemistry and Biochemical Neuropharmacology Research Laboratory, University of Karachi, Karachi, Pakistan
Correspondence: Erum Shireen Department of Biochemistry, Neurochemistry and Biochemical Neuropharmacology Research Laboratory, University of Karachi, Main University Road, Karachi 75270, Pakistan Tel +92 2l 9926 I3 I3 Ext 2289 Email eshireen@uok.edu.pk
Abstract: Antipsychotic drugs are extensively prescribed for the treatment of schizophrenia and other related psychiatric disorders. These drugs produced their action by blocking dopamine (DA) receptors, and these receptors are widely present throughout the brain. Therefore, extended antipsychotic use also leads to severe extrapyramidal side effects. The short-term effects include parkinsonism and the later appearing tardive dyskinesia. Currently available treatments for these disorders are mostly symptomatic and insufficient, and are often linked with a number of detrimental side effects. Antipsychotic-drug-induced tardive dyskinesia prompted researchers to explore novel drugs with fewer undesirable extrapyramidal side effects. Preclinical studies suggest a role of 5-hydroxytryptamine (serotonin)-1A and $2 \mathrm{~A} / 2 \mathrm{C}$ receptors in the modulation of dopaminergic neurotransmission and motivating a search for better therapeutic strategies for schizophrenia and related disorders. In addition, adjunctive treatment with antioxidants such as vitamin E, red rice bran oil, and curcumin in the early phases of illness may prevent additional oxidative injury, and thus improve and prevent further possible worsening of related neurological and behavioral deficits in schizophrenia. This review explains the role of serotonergic receptors and oxidative stress, with the aim of providing principles for prospect development of compounds to improve therapeutic effects of antischizophrenic drugs.

Keywords: antipsychotic drugs, tardive dyskinesia, parkinsonian-like symptoms, movement disorders

\section{Introduction}

\section{Antipsychotic drugs}

Antipsychotics were initially known as "neuroleptics" (from Latin, to take a grip of the neuron), since extrapyramidal side effects (EPSE) were considered fundamental for their curative properties. ${ }^{1}$ The antipsychotic is a group of drugs used to treat mental health conditions such as schizophrenia, agitation, severe anxiety, mania, and violent impulsive behavior in both adults and adolescents. These drugs produced their effects particularly by blocking dopamine (DA) receptors in the brain. Antipsychotic drugs can not only be categorized by their chemical structure but also be classified according to their pharmacology and clinical properties.

\section{Types of antipsychotic drugs \\ Typical antipsychotic drugs}

These are the most primitive neuroleptic drugs, dating from the early 1950s. The typical antipsychotic properties are accomplished through its antagonism at dopaminergic receptors. Haloperidol, the most commonly used conventional antipsychotic, 
is primarily effective in treating the positive signs of schizophrenia. The typical antipsychotic medications (eg, haloperidol or thioridazine), with or without psychosocial and environmental interventions, are frequently used to treat symptoms that occur in a majority of older patients with dementia during their illness courses and have been the mainstay of psychopharmacologic treatment during the past several decades. ${ }^{2}$

\section{Atypical antipsychotic drugs}

The "second generation" of neuroleptics was developed between the early 1960s and the 1980s. Initially, clozapine appeared as an innovatory drug with improved effectiveness over existing agents. ${ }^{3}$ The atypical neuroleptics are different from the older drugs concerning their mechanism of action. They exhibit less EPSE due to their combined effects on both dopaminergic and serotonergic receptors. Formerly, they were called atypical, because their propensity to cause dyskinetic symptoms in some patients was absent. It is now known that atypical neuroleptics also cause symptoms of tardive dyskinesia (TD), but such symptoms may take longer to manifest.

\section{Third-generation antipsychotic drugs}

These medications are the most recent to be developed and still carry the risk of causing dyskinesia. Since these are the newest medications available (developed since 2001), they are also the most costly. Aripiprazole is a fairly new antipsychotic drug that is used for the treatment of bipolar disorder and clinical depression but it is still not free from side effects. ${ }^{4}$

\section{Typical versus atypical antipsychotic drugs}

First-generation antipsychotics (FGAs) are classified according to their chemical structure, while second-generation antipsychotics (SGAs) are categorized according to their pharmacologic properties. The FGAs were effective, but the EPSE were often excruciating, which improved the usage of SGAs, which seem to have less risk for these effects. Due to this reason, conventional antipsychotics are usually substituted by the atypical antipsychotics. ${ }^{5}$ Some clinical studies have been conducted to find out the efficacy and safety of these drugs on neuropsychiatric symptoms, but contradictory results were obtained. ${ }^{6}$ Some meta-analyses and systematic reviews have provided only limited support for the superiority of SGAs. ${ }^{7-9}$ There was no substantial evidence that secondgeneration drugs were more effective and better tolerated for the treatment of negative symptoms or cognitive deficits. ${ }^{10}$ In this perspective, it has been suggested that typical antipsychotics are still as useful as atypicals in the treatment of schizophrenia. ${ }^{11}$ It has been found that none of the more recently developed antipsychotics except olanzapine have been shown to be superior to FGAs or even to achieve the level of clinical efficacy as attained with clozapine. ${ }^{12,13}$ The results are also equivocal regarding the incidence of EPSE in which, except for clozapine, no clear improvement was observed in EPSE profiles with newer antipsychotics. ${ }^{14,15}$ This failure is perhaps not surprising given the lack of clarity/ validity of the difference between typical versus atypical antipsychotics, or the distinction between FGAs, SGAs, and third-generation antipsychotics.

\section{Antipsychotic-drug-induced side effects}

Drug-induced side effects can sometimes be troublesome. There is often a trade-off between easing symptoms and having to put up with some side effects from treatment. Different antipsychotic medicines can have different types of side effects. Sometimes one medicine causes side effects in some people but not in others. At present, none of the antipsychotic is absolutely free from side effects; thus, the treatment with these agents involves balancing risks and benefits. We need to have better understanding of pharmacological principles that could enhance the efficacy and minimize the side effects of these agents. These medications induced side effects including TD and other related movement disorders. ${ }^{16-21}$ Many of them have other serious side effects such as agranulocytosis, a type of autoimmune disease in which the number of infectionfighting white blood cells are decimated. Neuroleptic malignant syndrome is a rare but potentially fatal disease that is associated with all classes of antipsychotic medication. ${ }^{22}$ The risk of sudden cardiac death is increased $>2.4$ times with both typical and atypical antipsychotic drugs. ${ }^{23}$ Extrapyramidal effects include parkinsonism, dystonia, and oropharyngeal dysphagia leading to an increased risk of pneumonia. ${ }^{24}$ Other side effects of atypical neuroleptics may include diabetes, inflammation of the pancreas, and weight gain. It is also known to cause insomnia as well as drowsiness, constipation, and vision problems. However, meta-analyses of clinical trials in participants with chronic schizophrenia have suggested a limited advantage of the newer agents in terms of efficacy ${ }^{7-9}$ and two recent large trials failed to find a difference between these two classes of antipsychotics. ${ }^{25,26}$ The quest for the search of more effective antipsychotic drugs with a lower occurrence of EPSE, therefore, remains highly relevant and represents an unmet research requirement for the finding of novel treatment strategies for schizophrenia and other disorders in which psychosis represents an important aspect, such 
as Huntington's disease. ${ }^{27,28} \mathrm{In}$ this review, we focused on the typical antipsychotic-induced movement disorders and possible therapeutic strategies for alleviating their undesirable side effects.

\section{Antipsychotic-induced parkinsonism and its treatment}

\section{What is parkinsonism?}

Major symptoms of parkinsonism include tremor, rigidity, akinesia, and postural instability. Currently, the term druginduced parkinsonism is nearly identical with antipsychoticinduced parkinsonism. However, drug-induced parkinsonism is a recurrent undesirable effect of several drugs that impede dopaminergic function particularly in the basal ganglia, ${ }^{29,30}$ including calcium antagonists, orthopramides, and substituted benzamides. ${ }^{29,31,32}$ DA receptors are extensively dispersed in the brain, and typical antipsychotics bind with dopaminergic receptors mainly in the striatum. Consequently, patients using these drugs are mostly at high risk of exhibiting parkinsonism and other related EPSE. Typical neuroleptic drugs such as haloperidol are extensively prescribed for the treatment of schizophrenia; their therapeutic effects are also associated with movement disorder, ${ }^{33}$ for instance, parkinsonian-like effects and TD are frequently described as EPSE. ${ }^{17,19,34}$ On the other hand, the risk for the development of EPSE was considered to be low for atypical antipsychotics such as clozapine, risperidone, olanzapine, and aripiprazole. It was believed that their relatively low incidence to induce EPSE was due to their potential antagonist activity at 5-hydroxytryptamine (5-HT)-2A receptors than DA receptors. ${ }^{35}$ Although, treatment with neuroleptics could elicit EPSE, these drugs still prove to be efficient in treating and managing schizophrenia and related behavioral disorders.

\section{Animal model of parkinsonism}

Two standard behavioral preclinical tests are used to evaluate the following:

1. When a D2 receptor antagonist such as haloperidol is administered to a rat, it will remain immobile for a given period of time when placed on an inclined surface. This immobility and/or frozen body posture is called catalepsy ${ }^{17,18,20,36,37}$ and caused by the blockade of DA receptors within the striatum and is considered to be a predictor of EPSE inducing potential in humans. ${ }^{36,38}$

2. The second test, the impairment of motor coordination, is also used as a predictor of antipsychotic-induced EPSE. A day before the treatment, animals are trained in a single session until they attain 150 seconds on the Rotor-Rod.
Anti-psychotic agents will impair its ability to attain 150 seconds on Rota-Rod. The latency to fall in a test session of 150 seconds will be taken as a measure of motor coordination. ${ }^{19-21}$

\section{Pathophysiology of parkinsonism}

Antipsychotic drugs have potential DA D2 receptor blocking capability, and the beneficial therapeutic effects of these drugs on psychosis are linked with their action on the reduction in dopaminergic transmission particularly in the limbic system. Antipsychotic-drug-induced striatal DA D2 receptor blockade produces initial disinhibition of gamma amino butyric acid (GABA)- and encephalin-containing striatal neurons after the disinhibition of the subthalamic nucleus. This leads to augmented thalamocortical GABAergic inhibition by enhancing the inhibitory projection from the globus pallidus/substantia nigra pars reticulata. This pathway is similar to the model of interruption of the basal ganglia motor loop in Parkinson's disease. Likewise, $>80 \%$ of D2 receptors were reported to be occupied in patients with EPSE who were using neuroleptics. ${ }^{39}$ Therefore, clinical symptoms of Parkinson disease started to appear when $>80 \%$ of nigral dopaminergic neurons had degenerated. In this respect, neuroleptic-induced motor disorders are known as parkinsonian-like symptoms. ${ }^{40}$

\section{Role of serotonin in parkinsonism}

The role of serotonergic system has been identified in the toning of dopaminergic neuronal activity. 5-HT (serotonin)-1A agonists and partial agonists are identified to elicit the anticataleptogenic effects, ${ }^{17,19,41-43}$ which is positively correlated with the rank order of their intrinsic activity at 5-HT-1A receptors. ${ }^{44}$ In order to find out the prospective role of somatodendritic and/or postsynaptic 5-HT-1A receptors in the modulation of haloperidol-induced catalepsy, $\mathrm{we}^{4}$ found a diminished availability of 5-HT in the striatum by the administration of partial agonist buspirone and selective 5-HT-1A agonist 8-hydroxy-2-(di- $n$-propylamino) tetralin $(8-\mathrm{OH}-$ DPAT) in rats owing to the stimulation of somatodendritic 5-HT-1A receptors. Therefore, dopaminergic neurotransmission was released from the inhibitory effect of 5-HT to attenuate haloperidol-induced catalepsy (Figure 1). On the other hand, postsynaptic 5-HT-1A receptors were occupied by $8-\mathrm{OH}-\mathrm{DPAT}$ and exerted an extra stimulatory influence on dopaminergic neuronal activity ${ }^{45}$ leading to the additional anticataleptogenic effects of 8-OH-DPAT compared with buspirone. ${ }^{17}$ By and large, these studies provide evidence that the stimulation of presynaptic in addition to postsynaptic 5-HT1A receptors augments DA neurotransmission particularly 


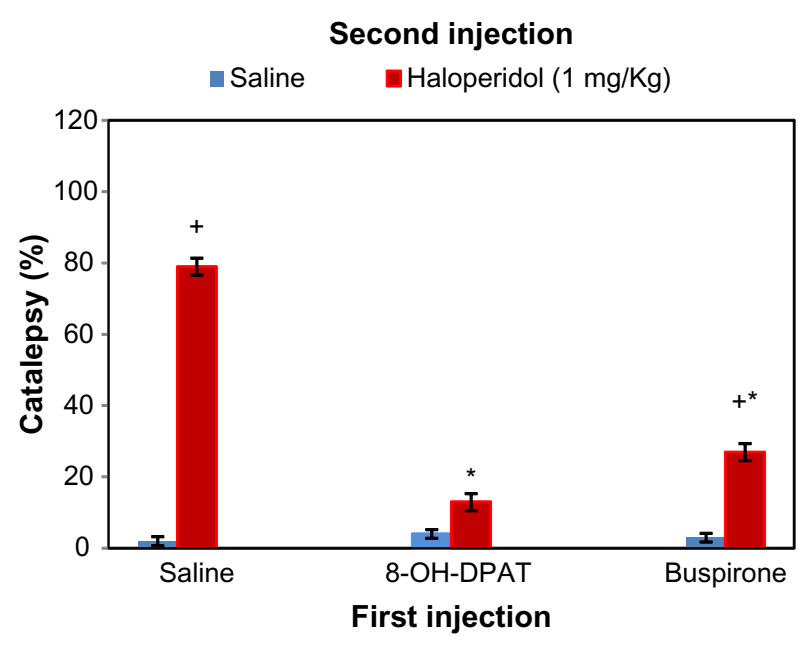

Figure I Cataleptic effects of haloperidol (I mg/ $\mathrm{kg})$ in saline, 8-OH-DPAT $(0.25 \mathrm{mg} / \mathrm{kg})$, or buspirone $(\mathrm{I} \mathrm{mg} / \mathrm{kg})$ pre-injected rats.

Notes: Values are mean $\pm S D(n=6), 30$ minutes after the administration of haloperidol. Significant differences by Newman-Keuls test: $* P<0.01$ in $8-O H$-DPAT or buspironeinjected animals as compared with respective saline-injected (first injection) controls. $+P<0.01$ in haloperidol-injected animals as compared with respective saline, $8-\mathrm{OH}-$ DPAT or buspirone-injected animals following the two-way ANOVA.

Abbreviations: ANOVA, analysis of variance; 8-OH-DPAT, 8-hydroxy-2-(di-npropylamino) tetralin; SD, standard deviation.

in the striatum. 5-HT-2C receptors are known to exert serotonergic inhibitory influence on the activity of dopaminergic neurons. These receptors are located on the cell body and terminal region of dopaminergic neurons. ${ }^{46,47}$

Therefore, the administration of mianserin and mesulergine, 5-HT-2A/2C receptor antagonists (Figures 2 and 3), possibly releases DA neurons from the inhibitory effects of 5-HT to ameliorate parkinsonian-like effects of the neuroleptics drug. ${ }^{20,48}$ This effect is illustrated in Figure 4.

In addition to drugs, certain physiological conditions may also have beneficial implications to treat or alleviate antipsychotic-induced side effects. We have found ${ }^{21}$ that repeated exposure to immobilization stress elicited a reversal of haloperidol-induced motor deficits in rats. It was proposed that somatodendritic 5-HT-1A and 5-HT-2C receptor desensitization following the exposure to uncontrolled stress contributes to the release of DA neurotransmission from the inhibitory effect of 5-HT. Conversely, an increase in the efficacy of postsynaptic 5-HT-1A receptors may also produced an excitatory influence on the activity of the dopaminergic neuron. Therefore, it was thought to be involved in the reversal of haloperidol-induced parkinsonian, like symptoms in rats exposed to repeated stress. ${ }^{21}$

\section{Antipsychotic-induced TD and its treatment \\ What is TD?}

The term "tardive dyskinesia" was coined in 1964 by Faurbye et al, ${ }^{49}$ and it is a syndrome of potentially irreversible, involuntary hyperkinetic movements particularly in the orofacial region,
Saline

Haloperidol $(1 \mathrm{mg} / \mathrm{kg})$
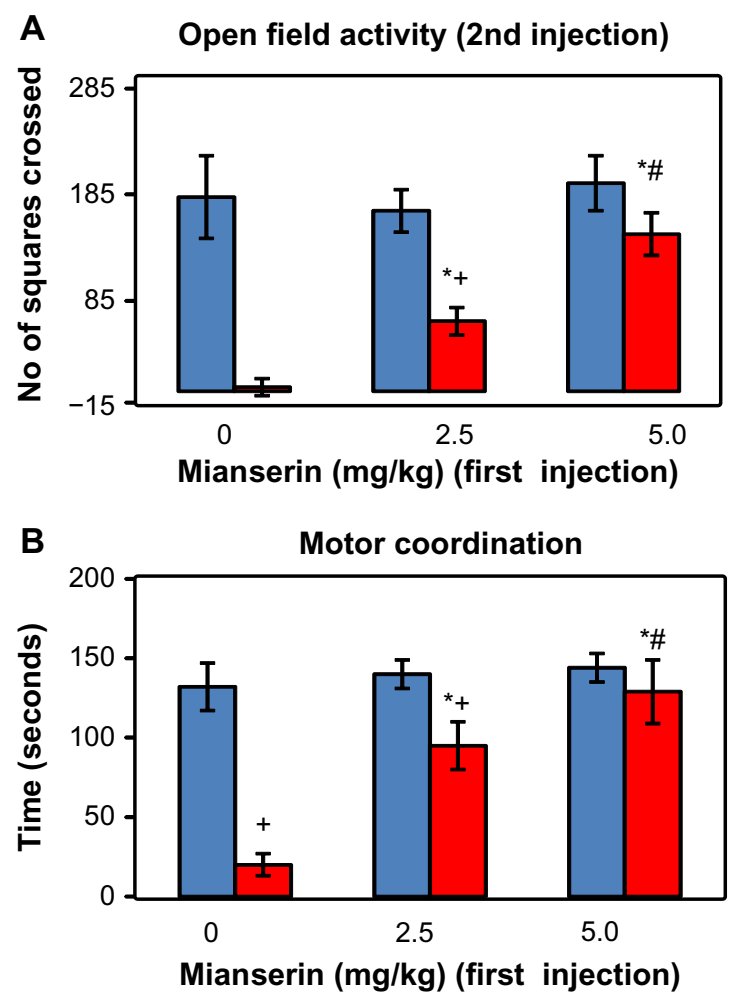

Figure 2 Effects of mianserin $(2.5$ and $5.0 \mathrm{mg} / \mathrm{kg}$ ) on haloperidol-induced deficits of exploratory activity (in an open field [A]) and motor coordination (B) on RotaRod in rats.

Notes: Values are mean $\pm S D(n=6), 30$ minutes after the administration of haloperidol. Significant differences by Newman-Keuls test. $* P<0.01$ from respective saline-injected controls, $+P<0.01$ from saline- plus haloperidol-injected animals, ${ }^{\#} P<0.01$ from mianserin- plus haloperidol-injected animals.

Abbreviation: SD, standard deviation.

which develops in patients during chronic neuroleptic treatment, and also it is a major limitation of neuroleptic therapy. ${ }^{19,34,49,50}$ Classical TD involves oral-buccal-lingual masticatory movements, which is characterized by repetitive jaw, face, and lingual movements (commonly protrusion) and may involve puffing of the cheeks, lip-smacking, puckering, and pursing, choreoathetoid movements in the limbs and trunk, guitar or piano playing movements, and other flexion and extension movements of the fingers and/or wrists. ${ }^{51}$ TD develops in $\sim 35 \%$ of patients administered long-term with typical antipsychotics ${ }^{52}$ and may be irreversible in approximately half of the patients. ${ }^{53}$

Epidemiological studies show that some factors such as age, institutionalization, a psychiatric diagnosis of mood disorders, and a history of acute extrapyramidal syndromes increase the risk of developing TD. It is more common in female patients. ${ }^{54}$

\section{Animal model of TD}

Animal models for TD have been developed to explore new treatment strategies for this disabling disease. ${ }^{19,21,41}$ 

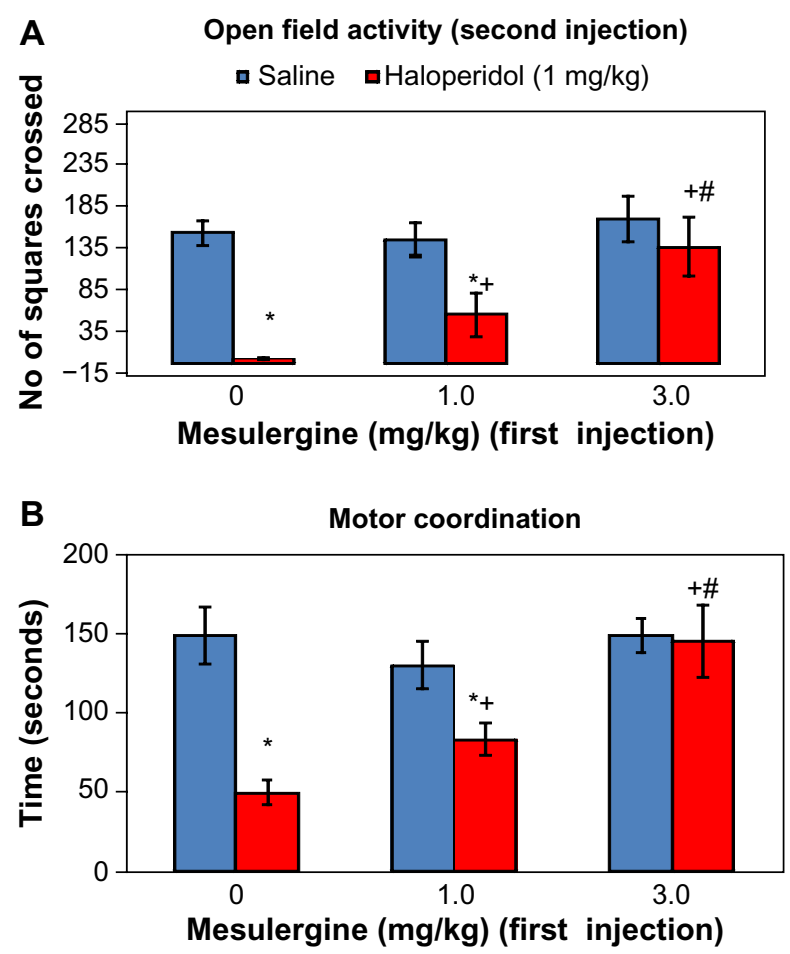

Figure 3 Effects of mesulergine $(1.0$ and $3.0 \mathrm{mg} / \mathrm{kg})$ on haloperidol-induced deficits of exploratory activity (in an open field [A]) and motor coordination (B) on RotaRod in rats.

Notes: Values are mean $+S D(n=6), 30$ minutes after the administration of haloperidol. Significant differences by Newman-Keuls test. $* P<0.01$ from respective saline-injected controls, $+P<0.01$ from saline- plus haloperidol-injected animals, ${ }^{\#} P<0.01$ from mesulergine- plus haloperidol-injected animals.

Abbreviation: SD, standard deviation.

Studies in animal models show that rats treated with chronic administration of antipsychotics exhibit vacuous chewing movements (VCMs) that show many classical characteristics of TD, including similarities in emergence, developmental time course, and response to dopaminergic drugs. ${ }^{55} \mathrm{VCMs}$ are generally described by purposeless mouth openings in the vertical plane, with or without tongue protrusion. ${ }^{55,56}$ Antipsychotic-induced VCMs seem to be in the same low frequency range $(1-3 \mathrm{~Hz})$ as TD symptoms in humans. ${ }^{56}$ Although rats are considered one of the best animal models, there are certain drawbacks of this model. Haloperidolinduced VCMs have been reported to normalize after drug withdrawal in some studies, ${ }^{57,58}$ but they may be irreversible in humans. ${ }^{59}$

\section{Pathophysiology of TD}

The pathophysiology of this disabling and frequently irreversible movement disorder is still vague. The longterm treatment with neuroleptics can induce some neuropathological changes in the central nervous system. ${ }^{60}$ However, most studies have focused on the biochemical or behavioral changes correlated with long-term antipsychotic

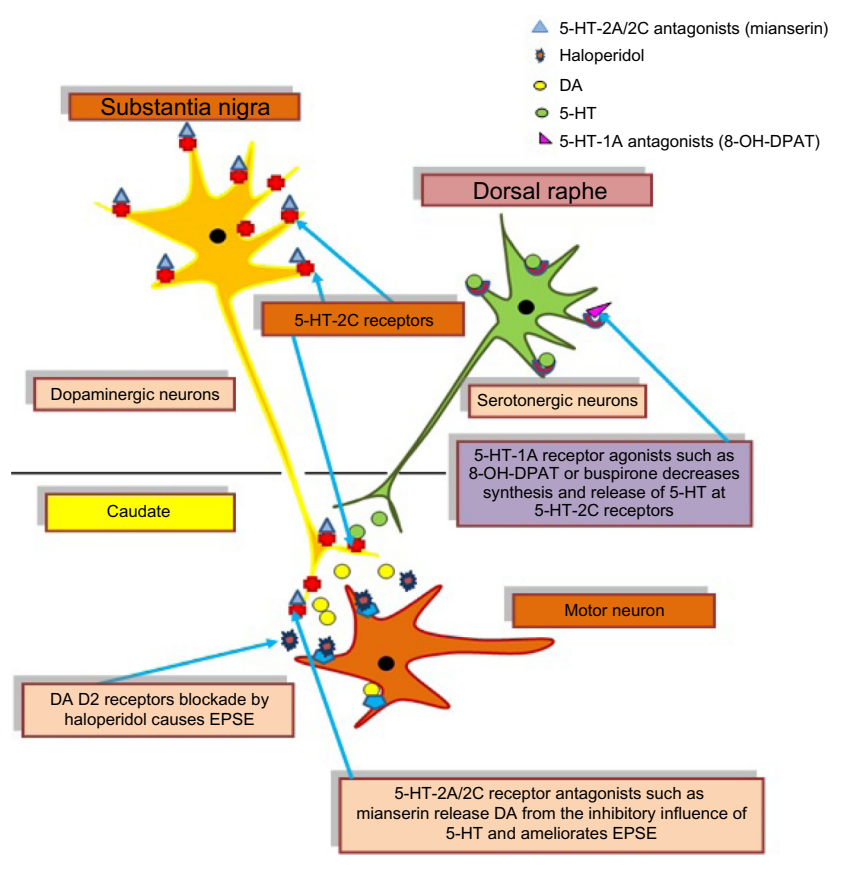

Figure 4 Role of 5-HT receptors in the modulation of haloperidol-induced EPSE. Abbreviations: DA, dopamine; EPSE, extrapyramidal side effects; 5-HT, 5-hydroxytryptamine; 8-OH-DPAT, 8-hydroxy-2-(di-n-propylamino) tetralin.

treatment. Several factors such as DA D2 receptor supersensitivity, GABAergic hypofunction, excitotoxicity, and oxidative stress (OS) have all been involved in the pathophysiology of TD. ${ }^{61,62}$ It has been hypothesized that chronic administration of antipsychotic causes postsynaptic DA receptor responsiveness in some studies, others reported an augmented behavioral response to DA agonists following long-term drug treatment ${ }^{63}$ and persistent DA D2 receptor occupancy. ${ }^{64}$ In addition, it was also proposed that increase in the effectiveness of somatodendritic and postsynaptic 5-HT-1A receptors after chronic treatment with haloperidol ${ }^{65,66}$ might reduce the normal inhibitory serotonergic influence on locomotor activity to exhibit late-appearing dyskinesia as observed in patients on typical antipsychotic therapy.

It has been found that administration of typical antipsychotics such as haloperidol produces a shrinkage or loss of tyrosine hydroxylase immunoreactive neurons particularly in the substantia nigra. On the other hand, a decrease in the tyrosine hydroxylase immunoreactivity was also observed in rat striatum. Both of these changes may be involved in the elicitation of VCMs. ${ }^{67,68}$

These alterations particularly take place in the nigrostriatal pathway but not in the mesolimbic DA system. ${ }^{69}$ It is therefore suggested that antipsychotic-induced brain morphological changes are the consequence of an enhanced DA metabolism that could raise intracellular DA 
concentration, followed by the inhibition of complex I, and increased OS. ${ }^{70}$ The pathophysiology is illustrated in Figure 5.

\section{Role of serotonin in TD}

5-HT-1A receptors are involved not only in the etiology of schizophrenia but also in the pathophysiology of TD. It has been found that postsynaptic 5-HT-1A receptors were upregulated in the postmortem brain samples of schizophrenic patients. ${ }^{71,72}$ Preclinical studies have also showed the role of 5-HT-1A receptors in the alleviation of TD. Thus, coadministration of buspirone, a 5-HT-1A receptor partial agonist, ${ }^{72,73}$ reversed reserpine-induced dyskinetic movements in a rat model of TD. ${ }^{74}$ 8-OH-DPAT, a selective 5-HT-1A agonist, inhibited haloperidol-induced VCMs in a dose-dependent manner. ${ }^{75}$ It has been reported from our laboratory that coadministration of buspirone at low doses reversed the induction of VCMs and 5-HT-1A receptor supersensitivity followed by the chronic administration of haloperidol. Therefore, a supersensitive somatodendritic serotonergic influence on the activity of dopaminergic neurons is possibly a causative component in the onset of TD and considered a novel treatment strategy for curing schizophrenia. ${ }^{19}$

\section{OS and TD}

There is a growing body of evidence that OS is involved in the pathology of major neuropsychiatric disorders.
Evidence from postmortem as well as peripheral tissues indicates alterations in both free radicals and antioxidant defense mechanisms in disorders such as schizophrenia and mood disorders. ${ }^{76}$ The long-term administration of typical neuroleptics, but not atypical, also decreases the levels of antioxidant enzyme, participating in the exacerbation of the oxidative events. ${ }^{77,78}$ In view of the OS generation, oxidative damage is detected when the production of reactive oxygen species surpasses the capability of the antioxidant system to remove them..$^{79}$ Additionally, the brain is more prone to the oxidative damage as compared with other organs or systems, ${ }^{80}$ as it contains high concentration of membrane lipids, excitotoxic amino acids, low levels of antioxidant defenses, and autoxidizable neurotransmitters. The neuronal phospholipid membrane contains polyunsaturated fatty acids that are more vulnerable to lipid peroxidation by reactive oxygen species than other lipids such as cholesterol and saturated fatty acids. ${ }^{81}$ Preclinical studies showed an increased rate of lipid peroxidation and peroxidative neuronal damage induced by the treatment with haloperidol. ${ }^{82}$ It was found that OS contributed to the toxicity of haloperidol, which activated a sequence of cellular processes leading even to cell death; the production of free radicals was an integral part of this cascade. ${ }^{76}$ The SGAs are reported to produce low risk of TD. But they still develop TD predominantly in older adults, perhaps due to the mechanisms that improve psychoses to overlap with those that could produce TD. ${ }^{83,84}$ Thus, there is

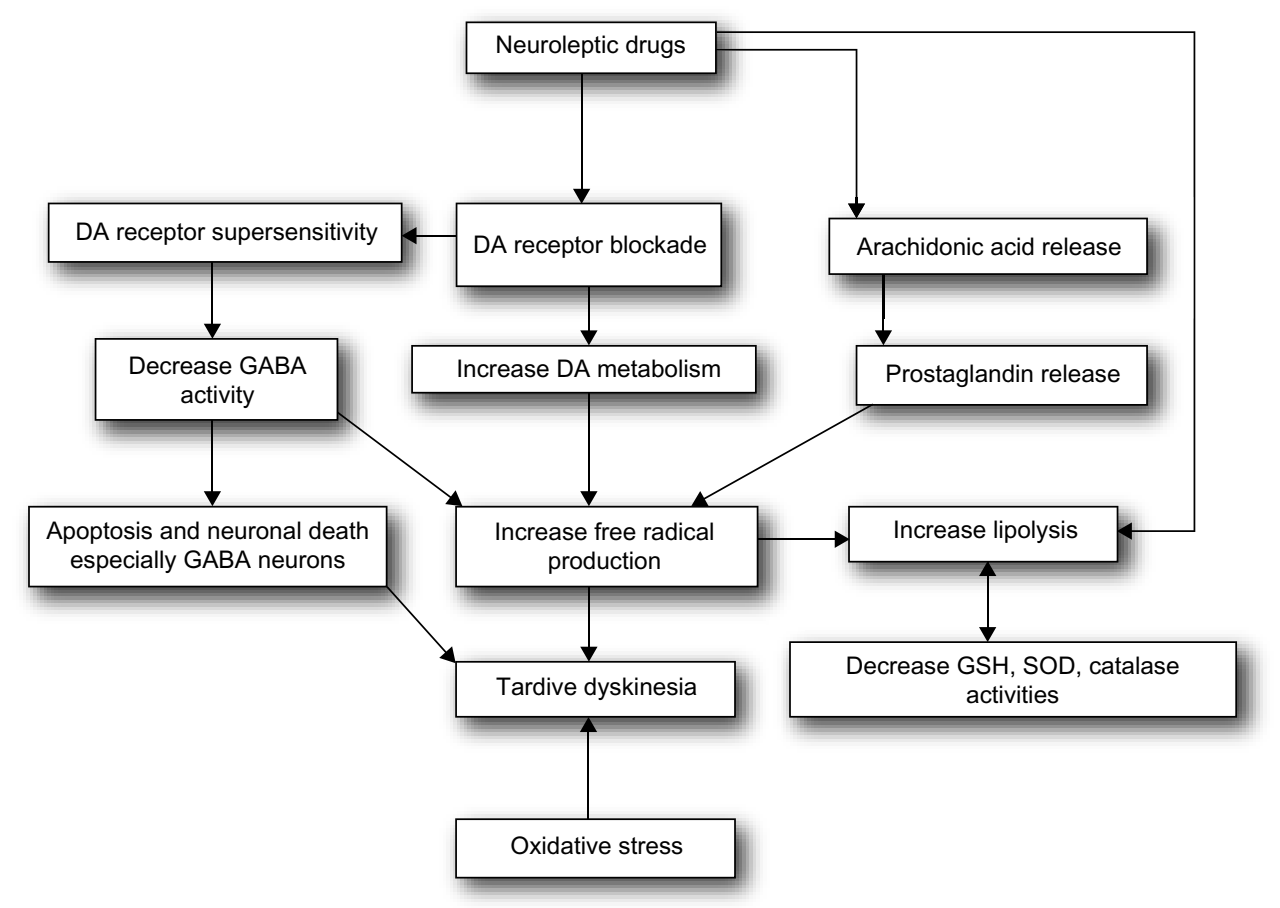

Figure 5 Proposed pathophysiological mechanisms of antipsychotic-induced TD.

Abbreviations: DA, dopamine; GABA, gamma amino butyric acid; TD, tardive dyskinesia; GSH, glutathione; SOD, superoxide dismutase. 


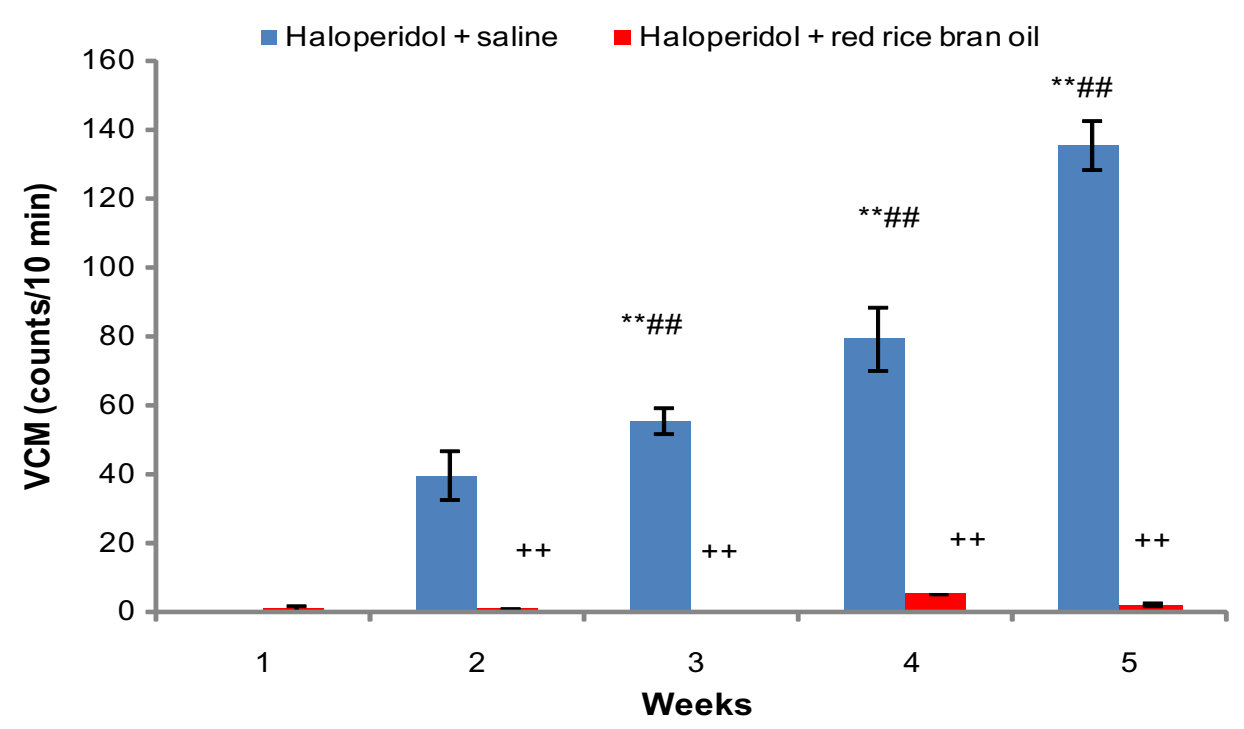

Figure 6 Time course effect of RRBO on haloperidol-induced deficits of vacuous chewing movements.

Notes: Values are mean \pm SD $(n=12)$. Significant differences by Newman-Keuls test. $* * P<0.0$ I from values of similarly treated animals, ${ }^{++} P<0.0$ I from respective week values of $W$-treated animals, and ${ }^{\#} P<0.01$ from respective week values of $W S$ and haloperidol- plus saline-treated animals.

Abbreviations: RRBO, red rice bran oil; SD, standard deviation; VCMs, vacuous chewing movements; W, water; S, saline; H, haloperidol.

a crucial requirement for better psychotic disorder management alternatives for or at least to lessen the side effects that develop with their use. Recently, the American Academy of Neurology presented the much-needed evidence-based guideline on the management of TD. ${ }^{85}$

\section{Treatment strategies for TD}

Recent studies from our laboratory have shown a reversal of haloperidol-induced parkinsonian-like effects and TD in rats cotreated with red rice bran oil (RRBO) ${ }^{86}$ as shown in Figure 6. It is tempting to relate protective and preventive effects of free radical scavenger RRBO with the reversal of haloperidol-induced TD. It is therefore suggested that incorporation of dietary supplementation-like RRBO having antioxidant properties can be useful to develop nutraceuticals for the treatment of schizophrenia.

Similarly, in other studies, antioxidant activity of hydroalcoholic extract of Brassica oleracea $^{87}$ is reported to be involved in the reversal of haloperidol-induced TD suggesting it as beneficial adjuvant in the treatment of drug-induced EPSE effects and related disorders. However, other preclinical studies have reported that administration of nicotine may be useful for improving the TD associated with antipsychotic uses. ${ }^{70}$ On the other hand, administration of curcumin reversed oxidative stress-induced TD in rats suggesting it as a promising therapeutic choice to treat this hyperkinetic movement disorder ${ }^{88}$ Related study presented a detailed review on positive results of nonneuroleptic agents in different trials, including tetrabenazine, amantadine, levetiracetam, piracetam, clonazepam, propranolol, vitamin B6, and Ginkgo biloba ${ }^{89}$ Clinical studies have shown that ginkgo biloba (240 mg/d for 12 weeks) was more helpful in reducing TD symptoms in people with schizophrenia. ${ }^{90}$ On the other hand, the administration of vitamin $\mathrm{B} 6^{91}$ and vitamin $\mathrm{E}^{92}$ (1,200 IU/d for 12 weeks) also proved to be effective in treating TD in clinical trials.

\section{Conclusion}

In conclusion, antioxidants are very low-risk drugs, and their use could be more beneficial as compared with the invented drugs, which, in most cases, produce undesirable side effects during their chronic treatment. Therefore, we suggest the use of antioxidants and serotonergic drugs as stand-alone intervention or as adjunct to conventional medications. They may provide attractive treatment strategic targets to manage antipsychotic-induced EPSE arising from dysfunctional serotonergic neurotransmission and OS. These studies suggest that antioxidants should be tried.

\section{Disclosure}

The author reports no conflicts of interest in this work.

\section{References}

1. Briles JJ, Rosenberg DR, Brooks BA, Roberts MW, Diwadkar VA. Review of the safety of second-generation antipsychotics: are they really "atypically" safe for youth and adults? Prim Care Companion CNS Disord 2012;14(3):11r01298.

2. Butler R, Radhakrishnan R. Dementia. Clin Evid. 2012;9:1001.

3. Kane J, Honigfeld G, Singer J, Meltzer H. Clozapine for the treatmentresistant schizophrenic: a double-blind comparison with chlorpromazine. Arch Gen Psychiatry. 1988;45:789-796.

4. Fountoulakis KN, Vieta E. Efficacy and safety of aripiprazole in the treatment of bipolar disorder: a systematic review. Ann Gen Psychiatry. 2009;8(16):16. 
5. Declercq T, Petrovic M, Azermai M, et al. Withdrawal versus continuation of chronic antipsychotic drugs for behavioural and psychological symptoms in older people with dementia. Cochrane Database Syst Rev. 2013;3:CD007726.

6. Ballard C, Waite J. The effectiveness of atypical antipsychotics for the treatment of aggression and psychosis in Alzheimer's disease. Cochrane Database Syst Rev. 2006;1:CD003476.

7. Geddes J, Freemantle N, Harrison P, Bebbington P. Atypical antipsychotics in the treatment of schizophrenia: systematic overview and meta-regression analysis. BMJ. 2000;321:1371-1376.

8. Leucht S, Wahlbeck K, Hamann J, Kissling W. New generation antipsychotics vs low-potency conventional antipsychotics: a systematic review and metaanalysis. Lancet. 2003;36:1581-1589.

9. Davis JM, Chen N, Glick ID. A meta-analysis of the efficacy of secondgeneration antipsychotics. Arch Gen Psychiatry. 2003;60:553-564.

10. Keefe RS, Bilder RM, Davis SM, et al; CATIE Investigators; Neurocognitive Working Group. Neurocognitive effects of antipsychotic medications in patients with chronic schizophrenia in the CATIE trial. Arch Gen Psychiatry. 2007;64:633-647.

11. Lewis S, Lieberman J. CATIE and CUTLASS: can we handle the truth? Br J Psychiatry. 2008;192(3):161-163.

12. Attard A, Taylor DM. Comparative effectiveness of atypical antipsychotics in schizophrenia: what have real-world trials taught us? CNS Drugs. 2012;26:491-508.

13. Hartling L, Abou-Setta AM, Dursun S, et al. Antipsychotics in adults with schizophrenia: comparative effectiveness of first-generation versus second-generation medications: a systematic review and meta-analysis. Ann Intern Med. 2012;157:498-511.

14. Pringsheim T, Doja A, Belanger S, Patten S. Treatment recommendations for extrapyramidal side effects associated with second-generation antipsychotic use in children and youth. Paediatr Child Health. 2011;16:590-598.

15. Haddad PM, Das A, Keyhani S, Chaudhry IB. Antipsychotic drugs and extrapyramidal side effects in first episode psychosis: a systematic review of head-head comparisons. $J$ Psychopharmacol. 2012;26(5Suppl):15-26.

16. Li CR, Chung YC, Park TW, et al. Clozapine-induced tardive dyskinesia in schizophrenic patients taking clozapine as a first-line antipsychotic drug. World J Biol Psychiatry. 2009;10:919-924.

17. Haleem DJ, Shireen E, Haleem MA. Somatodendritic and postsynaptic serotonin-1A receptors in the attenuation of haloperidolinduced catalepsy. Prog Neuropsychopharmacol Biol Psychiatry. 2004;28(8):1323-1329.

18. Haleem DJ. Serotonergic modulation of DA neurotransmission: a mechanism for enhancing therapeutics in schizophrenia. JCPSP. 2006;16(8):556-562.

19. Haleem DJ, Samad N, Haleem MA. Reversal of haloperidol induced extrapyramidal symptoms by buspirone; a time related study. Behav Pharmacol. 2007;18:147-153.

20. Shireen E, Naeem S, Inam QU, Haleem DJ. Oral administration of haloperidol at clinically recommended doses elicits smaller parkinsonian effects but more tardive dyskinesia in rats. PakJ Pharm Sci. 2013;26(2):271-276.

21. Shireen E, Pervez S, Masroor M, et al. Reversal of haloperidol induced motor deficits in rats exposed to repeated immobilization stress. Pak J Pharm Sci. 2014;27(5):1459-1466.

22. Strawn JR, Keck PE, Caroff SN. Neuroleptic malignant syndrome. Am J Psychiatry. 2007;164:870-876.

23. Ray WA, Chung CP, Murray KT, Hall K, Stein CM. Atypical antipsychotic drugs and the risk of sudden cardiac death. $N$ Engl $J$ Med. 2009;360:225-235.

24. KnolW, van Marum RJ, Jansen PA, Souverein PC, Schobben AF, Egberts AC. Antipsychotic drug use and risk of pneumonia in elderly people. $J \mathrm{Am}$ Geriatr Soc. 2008;56:661-666.

25. Lieberman JA, Stroup TS, McEvoy JP, et al; Clinical Antipsychotic Trials of Intervention Effectiveness (CATIE) Investigators. Effectiveness of antipsychotic drugs in patients with chronic schizophrenia. $N$ Engl J Med. 2005;353:1209-1223.
26. Jones PB, Barnes TR, Davies L, et al. Randomized controlled trial of the effect on quality of life of second- vs first-generation antipsychotic drugs in schizophrenia: cost utility of the latest antipsychotic drugs in schizophrenia study (CUtLASS 1). Arch Gen Psychiatry. 2006;63:1079-1087.

27. Alpay M, Koroshetz WJ. Quetiapine in the treatment of behavioral disturbances in patients with Huntington's disease. Psychosomatics. 2006;47:70-72.

28. Johnston TG. Risperidone long-acting injection and Huntington's disease: case series with significant psychiatric and behavioural symptoms. Int Clin Psychopharmacol. 2011;26:114-119.

29. Marti-Masso JF, Carrera N, Urtasun M. Drug-induced parkinsonism: a growing list [letter]. Mov Disord. 1993;8:125.

30. Gershanik OS. Drug-induced parkinsonism in the aged: recognition and prevention. Drugs Aging. 1994;5:127-132.

31. Perez-Gilabert Y, Mateo D, Gimenez-Roldan S. Actividad asistencial en una consulta hospital aria especializada en enfermedad de Parkinson y transtornos del movimiento: un estudio prospectivo durante anos [Care activities in a hospital clinic specializing in Parkinson's disease and movement disorders: a prospective study for years]. Neurologia. 1994;9:317-323. Spanish.

32. Jimenez-Jimenez FJ, Orti-Pareja M, Ayuso-Peralta L, et al. Druginduced parkinsonism in a movement disorders unit. A four-year survey. Parkinsonism Relat Disord. 1996;2:145-149.

33. Grohmann R, Koch R, Schmidt LG. Extrapyramidal symptoms in neuroleptic recipients. Agents Actions Suppl. 1990;29: 71-82.

34. Casey DE. Tardive dyskinesia: pathophysiology and animal models. J Clin Psychiatry. 2000;61:5-9.

35. Kuroki T, Nagao N, Nakahara T. Neuropharmacology of secondgeneration antipsychotic drugs: a validity of the serotonin-dopamine hypothesis. Prog Brain Res. 2008;172:199-212.

36. Haleem DJ, Batool F, Khan NH, et al. Differences in the effects of haloperidol and clozapine on rat brain serotonin and dopamine metabolism and on tests related to extrapyramidal functions in rats. Med Sci Monit. 2002;8:3354-3361.

37. Shireen E, Haleem DJ. Reversal of haloperidol-induced motor deficits by mianserin and mesulergine in rats. Pak J Pharm Sci. 2011;24(1):7-12.

38. Porsolt RD, Moser PC, Castagné V. Behavioral indices in antipsychotic drug discovery. J Pharmacol Exp Ther. 2010;333:632-638.

39. Farde L, Nordström AL, Wiesel FA, Pauli S, Halldin C, Sedvall G. Positron emission tomographic analysis of central D1 and D2 dopamine receptor occupancy in patients treated with classical neuroleptics and clozapine. Relation to extrapyramidal side effects. Arch Gen Psychiatry. 1992;49:538-544.

40. Shin H-W, Chung SJ. Drug-induced parkinsonism. J Clin Neurol. 2012;8:15-21.

41. Haleem DJ, Samad N, Haleem MA. Reversal of haloperidol-induced tardive vacuous chewing movements and supersensitive somatodendritic serotonergic response by buspirone in rats. Pharmacol Biochem Behav. 2007;87:115-121.

42. Prinssen EP, Kleven MS, Koek W. Interactions between neuroleptics and 5-HT(1A) ligands in preclinical behavioral models for antipsychotic and extrapyramidal effects. Psychopharmacology (Berl). 1999;144:20-29.

43. Haleem DJ, Khan NH. Enhancement of serotonin-1A receptor dependent responses following withdrawal of haloperidol in rats. Prog Neuropsychopharmacol Biol Psychiatry. 2003;27(4):645-651.

44. Prinssen EP, Colpaert FC, Koek W. 5-HT1A receptor activation and anticataleptic effects: high-efficacy agonists maximally inhibit haloperidol-induced catalepsy. Eur J Pharmacol. 2002;453: 217-221.

45. Haleem DJ. Extending therapeutic use of psychostimulants: focus on serotonin-1A receptor. Prog Neuropsychopharmacol Biol Psychiatry. 2013;46:170-180.

46. Esposito E. Serotonin-dopamine interaction as a focus of novel antidepressant drugs. Curr Drug Targets. 2006;7:177-185. 
47. Clemett DA, Punhani T, Duxon MS, Blackburns TP, Fone KC. Immunohistochemical localization of the 5 -HT-2C receptor protein in the rat CNS. Neuropharmacology. 2000;39:261-263.

48. Kapur S, Ramington G, Jones C, et al. High levels of dopamine D2 receptor occupancy with low dose haloperidol treatment: a PET study. Am J Psychiatry. 1996;153:946-950.

49. Faurbye A, Rasch PJ, Petersen PB, Brandborg G, Pakkenberg H. Neurological symptoms in pharmacotherapy of psychoses. Acta Psychiatr Scand. 1964;40:10-27.

50. Egan MF, Apud J, Wyatt RJ. Treatment of tardive dyskinesia. Schizophr Bull. 1997;23:583-609.

51. Revuelta GJ, Cloud L, Aia PG, Factor SA. Tardive dyskinesias. In: Albanese AJ, editor. Hyperkinetic Movement Disorders: Differential Diagnosis and Treatment. Chichester: Wiley-Blackwell 2012:331-352.

52. Dayalu P, Chou KL. Antipsychotic-induced extrapyramidal symptoms and their management. Expert Opin Pharmacother. 2008;9(9): 1451-1462.

53. Soares-Weiser K, Fernandez HH. Tardive dyskinesia. Semin Neurol. 2007;27(2):159-169.

54. Jeste DV, Caliguir MP. Tardive dyskinesia. Schizophr Bull. 1993;19: 303-315.

55. Waddington JL. Spontaneous orofacial movements-induced in rodents by very long term-neuroleptic administration: phenomenology, pathophysiology and putative relationship with tardive dyskinesia Psychopharmacology (Berl). 1990;101:431-447.

56. Kulkarni SK, Naidu PS. Animal models of tardive dyskinesia-a review. Indian J Physiol Pharmacol. 2001;45:148-160.

57. Marchese G, Casu MN, Bartholinic F, et al. Subchronic treatment with classical but not atypical antipsychotic produced morphological changes in rat nigrostriatal dopaminergic neurons directly related to early onset vacuous chewing. Eur J Neurosci. 2002;15: 1187-1196.

58. Zhang W, Perry KW, Wong DT, et al. Synergistic effects of olanzapine and other antipsychotic agents in combination with fluoxetine or norepinephrine and DA release in rat prefrontal cortex. Neuropsychopharmacology. 2000;23:250-262.

59. Gershanik OS, Gómez Arévalo GJ. Typical and atypical neuroleptics. Handb Clin Neurol. 2011;100:579-599.

60. Cadet JL, Kahler LA. Free radical mechanisms in schizophrenia and tardive dyskinesia. Neurosci Biobehav Rev. 1994;18: 457-467.

61. Wright AM, Bempong J, Kirby ML, Barlow RL, Bloomquist JR. Effects of haloperidol metabolites on neurotransmitter uptake and release: possible role in neurotoxicity and tardive dyskinesia. Brain Res. 1998;788:215-222.

62. Naidu PS, Singh A, Kulkarni SK. Effects of Withania somnifera root extract on reserpine-induced orofacial dyskinesia and cognitive dysfunctions. Phytother Res. 2006;20:140-146.

63. Jenner P, Marsden CD. Is the dopamine hypothesis of tardive dyskinesia completely wrong? Trends Neurosci. 1986;9:259-260.

64. Turrone P, Remington G, Noberga JN. The VCM model of TD revisited: is there a relationship to DA D-2 receptor occupancy? Neurosci Biobehav Rev. 2002;26:361-380.

65. Shireen E, Qurrat-ul-Ain, Batool F, Haleem DJ. Neurochemical effects of 8-OH-DPAT in rats treated with haloperidol. Pak J Pharm Sci. 2002;15(1):71-82.

66. Shireen E, Khan A, Batool F, Haleem DJ. Increase in serotonin-1A receptor responses following haloperidol withdrawal. J Basic Appl Sci. 2006;2(1):45-54.

67. Levinson AJ, Garside S, Rosebush PI, Mazurek MF. Haloperidol induces persistent down-regulation of tyrosine hydroxylase immunoreactivity in substantia nigra but not ventral tegmental area in the rat. Neuroscience. 1998;84:201-211.

68. Zhang Y, Xu H, He J, et al. Quetiapine reverses altered locomotor activity and tyrosine hydroxylase immunoreactivity in rat caudate putamen following long-term haloperidol treatment. Neurosci Lett. 2007;420:66-71.
69. Reynolds KB, Mac Gillivray L, Zettler M, Rosebush PI, Mazurek MF. Role of the dopamine transporter in mediating the neuroleptic-induced reduction of tyrosine hydroxylase-immunoreactive midbrain neurons. Brain Res. 2011;1394:24-32.

70. Bordia T, McIntosh JM, Quik M. Nicotine reduces antipsychoticinduced orofacial dyskinesia in rats. J Pharmacol Exp Ther. 2012;340:612-619.

71. Tauscher J, Kapur S, Verhoeff NP, et al. Brain serotonin 5-HT-1A receptor binding in schizophrenia measured by positron emission tomography and [11C]WAY-100635. Arch Gen Psychiatry. 2002;59: 514-520.

72. Gobert A, Rivet JM, Cisterilli L, Melon C, Millan MJ. Buspirone modulates basal and fluoxetine-stimulated dialysate levels of dopamine, noradrenaline and serotonin in the frontal cortex of freely moving rats: activation of serotonin-1A receptors and blockade of alpha-2-adrenergic receptors underlie its activation. Neuroscience. 1999;93:1251-1262.

73. Peroutka SJ. Selective interaction of novel anxiolytics with 5-hydroxytryptamine 1A receptors. Biol Psychiatry. 1985;20: 971-979.

74. Queiroz CM, Frussa-Filho R. Effects of buspirone on an animal model of tardive dyskinesia. Prog Neuropsychopharmacol Biol Psychiatry. 1999;23:1405-1418.

75. Naidu PS, Kulkarni SK. Effect of 5-HT-1A and 5-HT-2A/2C receptor modulation on neuroleptic-induced vacuous chewing movements. Eur J Pharmacol. 2001;428:81-86.

76. Pandya CD, Howell KR, Pillai A. Antioxidants as potential therapeutics for neuropsychiatric disorders. Prog Neuropsychopharmacol Biol Psychiatry. 2015;46:214-223.

77. Parikh V, Mohammad MK, Sahebarao PM. Differential effects of antipsychotics on expression of antioxidant enzymes and membrane lipid peroxidation in rat brain. J Psychiatr Res. 2003;37(1):43-51.

78. Pillai A, Parikh V, Terry AV, Mahadik SP. Long-term antipsychotic treatments and crossover studies in rats: differential effects of typical and atypical agents on the expression of antioxidant enzymes and membrane lipid peroxidation in rat brain. J Psychiatr Res. 2007;41(5):372-386.

79. Jenkins RR, Goldfarb A. Introduction-oxidant stress, aging, and exercise. Med Sci Sports Exerc. 1993;25:210-212.

80. Halliwel B, Gutteridge JMC. Free Radicals in Biology and Medicine. 3rd ed. Oxford: Oxford University Press; 1999.

81. Evans DR, Parikh VV, Khan MM, Coussons C, Buckley PF, Mahadik SP. Red blood cell membrane essential fatty acid metabolism in early psychotic patients following antipsychotic drug treatment. Prostaglandins Leukot Essent Fatty Acids. 2003;69:393-399.

82. Sagara Y. Induction of reactive oxygen species in neurons by haloperidol. J Neurochem. 1998;71:1002-1012.

83. Correll CU, Leucht S, Kane JM. Lower risk for tardive dyskinesia associated with second-generation antipsychotics: a systematic review of 1-year studies. Am J Psychiatry. 2004;161:414-425.

84. Tarsy D, Lungu C, Baldessarini RJ. Epidemiology of tardive dyskinesia before and during the era of modern antipsychotic drugs. Handb Clin Neurol. 2011;100:601-616.

85. Bhidayasiri R, Fahn S, Weiner WJ, et al. Evidence-based guideline: treatment of tardive syndromes: report of the Guideline Development Subcommittee of the American Academy of Neurology. Neurology. 2013;8:463-469.

86. Naz F, Shireen E. Suppression and treatment of haloperidol induced extrapyramidal side effects and anxiety syndrome by the coadministeration of red rice bran oil in rats. Int J Endors Health Sci Res. 2014;2(2):82-92.

87. Nagarjuna S, Arifullah M, Kumar AS, et al. Evaluation of antioxidant and antiparkinsonian activities of Brassica oleracea in haloperidolinduced tardive dyskinesia. Int J Green Pharm. 2015;9(3):143-149.

88. Bishnoi M, Chopra K, Kulkarni SK. Protective effect of Curcumin, the active principle of turmeric (Curcuma longa) in haloperidolinduced orofacial dyskinesia and associated behavioural, biochemical and neurochemical changes in rat brain. Pharmacol Biochem Behav. 2008;88:511-522.

89. Cloud LJ, Zutshi D, Factor SA. Tardive dyskinesia: therapeutic options for an increasingly common disorder. Neurotherapeutics. 2014;11(1):166-176. 
90. Zhang WF, Tan YL, Zhang XY, Chan RC, Wu HR, Zhou DF. Extract of Ginkgo biloba treatment for tardive dyskinesia in schizophrenia: a randomized, double-blind, placebo-controlled trial. J Clin Psychiatry. 2011;72(5):615-621.

91. Lerner V, Miodownik C, Kaptsan A, et al. Vitamin B6 in the treatment of tardive dyskinesia: a double-blind, placebo-controlled, crossover study. Am J Psychiatry. 2001;158:1511-1514.
92. Zhang XY, Zhou DF, Cao LY, Xu CQ, Chen DC, Wu GY. The effect of vitamin $\mathrm{E}$ treatment on tardive dyskinesia and blood superoxide dismutase: a double-blind placebo-controlled trial. J Clin Psychopharmacol. 2004;24(1):83-86.

\section{Publish your work in this journal}

The Journal of Experimental Pharmacology is an international, peerreviewed, open access journal publishing original research, reports, reviews and commentaries on all areas of laboratory and experimental pharmacology. The manuscript management system is completely online and includes a very quick and fair peer-review system.
Visit http://www.dovepress.com/testimonials.php to read real quotes from published authors. 